\title{
Contra del odio, la intolerancia y la segregación: diversidad e interculturalidad en la educación ciudadana del nuevo Chile
}

\author{
Against hatred, intolerance and segregation: diversity and \\ interculturality in citizenship education in the new Chile
}

\author{
ANDRÉS PARADA OLIVARES \\ Universidad Metropolitana de Ciencias de la Educación, Santiago, CHILE (andres.parada2O21@ \\ umce.cl)(https://orcid.org/ 0000-0002-6710-6307) \\ DR. PEDRO RODRÍGUEZ ROJAS \\ Universidad Central de Chile, Santiago, Chile (pedrorodriguezrojas@gmail.com)(https://orcid \\ org/0000-0003-1347-8313)
}

\section{RESUMEN}

Diversidad e interculturalidad son dos conceptos que nutren la idea de una nueva educación para la ciudadanía, principalmente debido a sus reinterpretaciones conceptuales y sus nuevas estructuras epistemológicas, las cuales, rompen paradigmas colonialistas con propuestas que motivan una nueva comprensión de Latinoamérica y Chile. El objetivo es revisar los conceptos diversidad e interculturalidad para establecer de qué manera ambas ideas pueden potenciar la educación ciudadana en Chile. Para el desarrollo investigativo se optó por una metodología de trabajo estructurada en base a un análisis documental, descriptivo y temático. Es posible concluir que, a la luz de los acontecimientos que vive el país, se requiere vincular la educación ciudadana escolar con propuestas que trasciendan a los conocimientos cívicos tradicionales y que, por lo tanto, promuevan relaciones civiles que permitan el buen vivir para articular un mejor convivir.

\section{ABSTRACT:}

Diversity and interculturality are two concepts that nurture the idea of a new education for citizenship, mainly due to their conceptual reinterpretations and their new epistemological structures, which break colonialist paradigms with proposals that motivate a new understanding of Latin America and Chile. The objective is to review the concepts of diversity and interculturality in order to establish 
how both ideas can enhance citizenship education in Chile. For the research development, a structured work methodology has been chosen based on a documentary, descriptive and thematic analysis. It is possible to conclude that, in light of the events that the country is experiencing, it is necessary to link school citizenship education with proposals that transcend traditional civic knowledge and that, therefore, promote civil relations that allow good living in order to articulate a better coexistence.

\section{PALABRAS CLAVES / KEY WORDS}

Diversidad, interculturalidad, educación ciudadana. / Diversity, interculturality, citizenship education.

\section{INTRODUCCIÓN}

El movimiento social iniciado en octubre de 2019 cimentó el deseo justo de un mejor país, una nueva convivencia, nuevas reglas que permitan una vida más digna y justa para todas y todos. Maturana (2019) planteaba que los seres humanos hacemos teorías con las cuales justificamos lo que hacemos. Bajo esta propuesta, es posible preguntarse: ¿Cuáles son las teorías que sustentan lo que pasa hoy en la actividad de enseñar a nuevos ciudadanos y ciudadanas? ¿Están esas teorías pensadas en los nuevos parámetros de convivencia que en la actualidad surgen en Chile y también en Latinoamérica? Finalmente es válido preguntarse: ¿Qué ciudadanía y para qué democracia? Las ideas que se plasman en este escrito surgen de lo que pudiéramos denominar una coyuntura histórica. Pero también se sostienen en la esperanza de la colaboración, en el anhelo real de contribuir con nuevas ideas para los nuevos rumbos que en Chile se empiezan a tomar.

Los aprendizajes ciudadanos se sustentan en la capacidad biológica que tenemos de relacionarnos, es lo que Dávila y Maturana (2015) denominaron unidades ecológicas organismos - nichos, siendo estos un espacio natural donde los seres vivos se relacionan entre sí constituyéndose en el lenguaje. La convivencia sin duda es necesaria en la formación de una ciudadanía, así queda plasmado en las diferentes normativas existentes en Chile, por ejemplo, La Ley General de Educación de 2009, establece que uno de sus fines, en el ámbito social

\footnotetext{
Es desarrollar el aprecio de los fundamentos de la vida democrática y sus instituciones, los derechos humanos y valorar la participación ciudadana activa, solidaria y responsable, con conciencia de sus deberes y derechos, y respeto por la diversidad de ideas, formas de vida e intereses (p.11).
}

A la luz de lo antes planteado, la pregunta que induce estas reflexiones es ¿Desde qué 
propuestas conceptuales es posible repensar los aprendizajes ciudadanos? El presente ensayo pretende abrir posibilidades de un reencuentro de lo existente, en materia de educación ciudadana y lo que pudiera existir para enriquecer esos aprendizajes a partir del análisis de los conceptos de diversidad e interculturalidad. El trabajo metodológico se estructuró en base a un análisis documental, descriptivo y temático que permitió el reconocer, vincular y describir las posibilidades teórico prácticas que emergen desde las ideas de diversidad e interculturalidad con el fin de tensionar la propuesta de educación ciudadana escolar del sistema educativo chileno.

\section{EL CHILE QUE SE RECONSTITUYE EN LA CONSTITUYENTE}

El devenir histórico le pertenece a la comunidad y su esperanza de un Chile mejor. Sin duda hoy nos adentramos en un cambio epocal. El estallido social de 2019, el plebiscito de 2020, y en la actualidad, la instalación de la convención constitucional, nos pone frente a un tiempo de iniciativas. Como nunca antes en la historia de Chile, es posible que todas y todos podamos pensar en cómo vivir y convivir con dignidad e igualdad de oportunidades. El devenir del país, desde octubre de 2019, se constituyó, para la gran mayoría de los chilenos y chilenas, en una oportunidad. El dolor, la impotencia de años y la incertidumbre convocaron a la sociedad, por medio de la movilización, a denunciar el derrumbe del legado institucional construido por la dictadura cívico - militar, encabezada por Augusto Pinochet, pero, además, se alzó la voz sobre la decadencia del nuevo orden impuesto por los gobiernos posteriores a la dictadura. "Chile despertó" fue una de las consignas que con más fuerza se escuchó durante el movimiento social, esa consigna es el reflejo de lo que vivimos hoy en Chile, despertamos y con tal lucidez debemos disponernos para aprender, nuevamente, a reconocernos y aceptarnos en un nuevo pacto social pero esta vez conscientes de nuestra propia historia.

Pretender que dejar de mirar el pasado sea una buena opción, en estos tiempos coyunturales, es un error. En el estadio Nacional de Chile yace la frase "Un pueblo sin memoria no tiene futuro", esta frase se resiste a la soledad y combate el paso del tiempo con la función de exigirnos no olvidar que hubo un momento en donde el proyecto político de la mayoría fue silenciado por el proyecto político de unos pocos. Esto que sucedió en el siglo pasado sigue siendo parte de aquello que remece nuestras realidades hoy en el siglo $X X I$. Lo antes mencionado es posible evidenciarlo en alocuciones políticas, tremendamente contemporáneas y muy significativas para millares de chilenos y chilenas.

Y con la conciencia histórica de que somos una posta más larga que nuestras experiencias vitales, podemos decir hoy día con mucha alegría, con mucha esperanza, como hemos repetido en las plazas de nuestro país, en las regiones, en los espacios más recónditos, que si Chile fue la cuna del neoliberalismo también será su tumba compañeros y compañeras. G. Boric (Comunicación personal, 18 de julio, 2021). 
A partir de los acontecimientos de octubre de 2019 el pueblo de Chile se levantó en contra de todo aquello que los oprimió, engañó e ilusionó falsamente. Los chilenos y chilenas comprendieron que los denominados representantes del pueblo más que encarnar sus anhelos velaron por los propios, en este sentido Gabriel Salazar (2020) planteó que las élites políticas “usurparon la soberanía para auto-representarse y auto-reproducirse. Y a la larga, sentirse dueños de la soberanía popular" (p. 17). Lo que sucedió, esta pasando y está por acontecer en Chile es la consecuencia de lo que el biólogo y filósofo Humberto Maturana (2021) junto a la epistemóloga Ximena Dávila (2021) describieron como “un cansancio respecto de la forma en que el poder se impone, un alzamiento frente a la psiquis del poder mal entendido" (p. 43). La revuelta social mostró, a escépticos y creyentes, de la manera más real y cruel posible, la desigualdad que impera en Chile. Diferencias que los gobiernos no habían querido ver, pero que estuvieron siempre presentes para organizaciones supranacionales

La realidad estaba disponible para quien quisiera verla, en cada reporte de la OCDE, cada estudio del Banco Mundial, cada ranking de competitividad, cada reflexión de economistas, sociólogos que, al mirar a Chile, advertían un país fracturado. De hecho, los gritos de la calle y los informes de la OCDE dicen básicamente lo mismo: demasiada desigualdad, demasiado nepotismo, demasiados abusos. (Matamala, 2019, p. 22).

Visibilizar lo antes descrito permite acabar con la legitimación de una de las estructuras sociales más desiguales de la región Latinoamericana, la necesidad de nuevos consensos y paradigmas de convivencia social son urgentes. La desvalorización del ideal democrático y la subjetivación de los derechos humanos, sin duda, son parte de las consecuencias de lo que Bauman (1999) caracterizó como una acelerada "modernidad líquida" es decir, una comunidad que fluye cambiando de forma constante entre márgenes de convivencia civil y cívicas impuestas por los parámetros de un sistema neoliberal que ha cautivado a la democracia para el cumplimiento de sus propios intereses. Sin embargo, la coyuntura actual ha demostrado, en Chile y Latinoamérica que "se desmorona la idea conservadora de que no hay alternativa a la forma de vida impuesta por el hipercapitalismo en el que vivimos" (De Sousa Santos, 2020, p. 22). Los gobiernos en Chile, abierta o solapadamente, fueron custodios de las ideas neoliberales y en consecuencia férreos defensores de la integración de las ideologías del mercado y el lucro en instituciones como la educación.

Este momento, de terribles realidades, de profundas incertidumbres no tiene porqué ser necesariamente un tiempo de espera o contemplación pasiva, puede ser, sin duda, una coyuntura para, como plantea Catherine Walsh (2009), habitar las grietas y desde ahí comenzar un camino que permita comprometerse con nuevos conocimientos para una nueva episteme. Estela Quintar (2008) propone que, "la postura epistémica es fundante porque tiene que ver con la opción ético - política desde la cual me paro a mirar. No es lo mismo observar desde una postura analítica, que desde una postura crítico - hermenéutica". (p. 134) Se hace necesario el ejercicio del reconocimiento personal y colectivo con el fin de emprender refundaciones sociales, políticas, económicas, culturales y étnicas.

El Chile que hoy convivimos es un lugar en reconstrucción, pero se debe forjar desde lo más profundo y complejo del entramado social e histórico. El Chile que deseamos requiere nuevas posturas, pensamientos y acciones que movilicen los anhelos más coherentes y reales 
del conjunto social. En este aspecto Maturana y Dávila (2021) por medio de una reflexión desde la biología cultural, tanto en forma como en el fondo permiten aventurar el futuro social al cual deberíamos mirar,

\begin{abstract}
Un árbol no compite con otro árbol para definir cuál es más fuerte, más alto o cuál logra dominar mejor su entorno. Al contrario, diríamos que existen y se conservan espontáneamente en una red armónica de sobrevivencia acoplados a su medio. (p. 11)
\end{abstract}

La reflexión antes propuesta permite comprender el anhelo del fenómeno social que inició en 2019 y concluyó, en 2021, con la instalación de la Convención Constituyente. En este escenario es un deber, para la investigación educativa, disponer el pensamiento sobre aquello que nos pasó, y, por ende, sobre todo lo que deseamos que nos pase en el futuro. "Hoy se funda un nuevo Chile" fueron las palabras con las que la presidenta de la comisión constituyente, Elisa Loncón, sentenció su discurso inaugural el domingo 4 de julio de 2021. Hoy como nunca antes en la historia de Chile, es posible que todas y todos podamos pensar en vivir y convivir con dignidad e igualdad de oportunidades. En resonancia con lo antes dicho, será trascendental construir nuevos saberes que fomenten una renovada pedagogía para una renovada educación que promueva los sentidos sociales, culturales, políticos y económicos plasmados en la novel constitución.

La realidad que anhelamos será necesaria enseñarla, el nuevo Chile debe aprenderse. El ejercicio antes mencionado, inicialmente es una búsqueda de nuevos paradigmas, otras formas de vida que no deriven del modelo neoliberal, tal como lo plantea Lander (2000) Las alternativas al neoliberalismo como a lo que representan en la vida, no admiten otro sistema porque se fundamentan el lo liberal.

Con posterioridad, Boaventura de Sousa Santos (2012) corroboró lo que Lander ya planteaba once años antes, "las crisis se profundizan, al mismo tiempo que no existen grandes alternativas" (p. 13). Una década después es posible establecer que aquella falta de alternativas fue consecuencia de la dominación del neoliberalismo, movimiento ideológico - técnico que permeó las instituciones político sociales, como la educación. La intención fue, y es, poner a instituciones sociales, como la escuela, al servicio de los intereses del modelo capitalista. Habermas (1972) planteó que el interés fundamental que orienta a la ciencia empírico - analítica consiste en el control y la posibilidad de la explotación técnica del saber.

El escenario antes descrito exige distinguir los componentes científicos, sociológicos y filosóficos que permitieron el ordenamiento social, político y económico que en la actualidad inicia su proceso de derrumbe, por lo menos en Chile. Intelectuales como Antonio Gramsci, Pierre Bourdieu y Michel Foucault se transforman en referentes teóricos, en particular bajo el actual escenario sociopolítico por el cual atraviesa Chile y Latinoamérica. Volver sobre los constructos científicos y las teorías que nos explican la conformación de la sociedad se convierte en una necesidad, un paso previo, a la puesta en marcha de cualquier intento de investigación o propuesta de colaboración científica que invite al repensar el nuevo Chile. Dominación, desigualdad, perpetuidad de los privilegios, reproducción, control, violencia estatal y disciplina del cuerpo y las mentes son conceptos y acciones que parecen ser representativos del devenir de Chile, con más claridad, desde el golpe de Estado de 1973. 
En el pensamiento de Bourdieu está el cuestionamiento al o los campos de dominación, es decir, lo medular del pensamiento de Bourdieu está en constatar y denunciar como el o los sistemas, construidos en el neoliberalismo, perpetúan los privilegios y la desigualdad. Entonces vale preguntarse ¿Cómo es el Chile que se pretende dejar atrás desde la óptica de Bourdieu? Partamos mirando el Estado en la lógica del estudio de Bourdieu (2012) quien plantea que: "entre las funciones del Estado se encuentra, evidentemente, la producción de identidad social legítima, esto quiere decir que, aunque alguien no esté de acuerdo con estas identidades, tiene que poseer una" (p.15). En este acercamiento sobre las imposiciones estatales es posible evidenciar un proceso de homogeneización que no pretende reconocer aquello que no es parte del espacio que, desde el poder, se construye. Es esta condición, así lo cree Bourdieu (2012), fuente de alzamientos o levantamientos al momento de reconocer aquella homogeneización forzada de una identidad que no hace sentido frente a una comunidad construida por algunos pocos. Es decir:

Una parte de las conductas sociales, como la rebelión, puede estar determinada por las categorías mismas contra las que se rebela quien se rebela. Se trata de uno de los grandes principios de explicación sociológica: Ios que tienen dificultades con el sistema escolar están a menudo determinados por sus propias dificultades y algunas carreras intelectuales están totalmente determinadas por una relación desafortunada con el sistema escolar, o sea, por un esfuerzo por desmentir, sin saberlo, una identidad legítima impuesta por el Estado. (p. 16)

En el origen de la lucha está el reconocimiento, de la mayoría, de una condición obligatoria casi hereditaria de miseria y desigualdad, por lo tanto, lo que pasó en Chile fue que los dominados entendieron que mucho de lo que estaban condenados a ser no era más que una estratagema pensada para perpetuar un status quo social, económico y político. En las ideas del mismo Bourdieu (2012) es posible encontrar una caracterización de lo dicho cuando advierte que no existe forma de legislar lo cultural en el ser social.

Históricamente los saberes de los sujetos que resisten, es decir, que no pertenecen al grupo de intelectuales y poderes oficiales, en algún momento cobran relevancia en el entendimiento de su condición de sometimiento. Según Foucault (1984) nacemos, vivimos, convivimos y existimos en una comunidad política que está pensada desde la normalización. En definitiva, sujeto social y objeto político, desde la lógica de Pierre Bourdieu y Michel Foucault se construyen desde las acciones que perpetúan y dominan los campos sociales imponiendo como válidos entramados de poder que se establecen como la realidad objetiva. Las instituciones del Estado son organismos que están al servicio de la construcción de espacios de redes que norman con el fin de servir a sus intereses. Uno de esos espacios fueron las instituciones educativas, estas sirvieron y han servido de promoción y validación de lo que Gramsci (1990) Ilamó “políticas de dominación”. 


\section{LO QUE PASA EN EDUCACIÓN Y A LO QUE DEBIÉRAMOS ASPIRAR}

Desde la instauración del sistema económico neoliberal en Chile, afianzado legalmente por la constitución política de 1980, el sistema escolar se constituyó en un brazo institucional de políticas de poder que permitieron la normalización e implementación de los designios de dicha ideología. Sin embargo, hoy, todas y todos los que constituyen ese sistema tienen la posibilidad de reobservarlo y reflexionarlo para iniciar, a través de pequeñas reconstrucciones, una total refundación. La esperanza de un mejor mañana para los chilenos y chilenas dependerá mucho de lo que ocurra, o no, al interior de las escuelas, los colegios, los jardines infantiles y las universidades. Lo antes descrito requerirá de crear, proponer, intervenir en el orden existente, una "práctica de insurgencia" en palabras de Catherine Walsh (2009).

El futuro de la sociedad está históricamente ligado con lo que pasa, o se intencione que pase, en los sistemas educativos. En este contexto Pagès (2015) deja entrever los nuevos sentidos que la escuela debe perseguir a propósito de repensar sus responsabilidades sociales y políticas. "El propósito fundamental de la escuela obligatoria y, en consecuencia, de las enseñanzas y de los aprendizajes que en ella se generan -o que se deberían generar-, es formar a la ciudadanía para su presente y para su futuro" (p. 6). Cabe preguntarse entonces, ¿Cuáles son las ideas que se requieren para la enseñanza de los futuros ciudadanos y ciudadanas? es decir, ¿Qué tipo de comunidad es la que deseamos construir desde los centros educativos? ¿Cuáles son las ideas que deben constituirse en pilares de los nuevos conocimientos que articulen la nueva ciudadanía a la que se aspira? Estas preguntas invitan al profesorado, a los investigadores e investigadoras en educación a rebelarse contra la domesticación de la pedagogía y la investigación positivista. Carlos Calvo (2012) planteó que, “la asistematicidad existe en términos del paradigma científico vigente, que es el dominante en el sistema escolar; sin embargo, no hay tal asistematicidad cuando las relaciones causales, propias de la ciencia actual, coexisten con relaciones causales y sincrónicas" (p. 184). En definitiva, la educación y sus actores viven y conviven en la creencia de que aquello que ocurre, por ejemplo, al interior del aula es lo adecuado, lo único, válido, que debe pasar al interior del proceso educativo. La paradoja antes mencionada describe la "tan profunda la obsesión por el carácter científico de la labor escolar que se pasa por alto que no es posible que un fenómeno y proceso educativo no forme parte del sistema total de la cultura escolar creada" (Calvo, 2012, p. 185). El desafío es construir la escuela desde los saberes y experiencias del profesorado junto con las lecciones que deja la convivencia con los y las estudiantes.

La legitimación científica de los mecanismos de control, homogeneización y sometimiento de la comunidad dominaron la vida civil y cívica. Encauzaron, a su conveniencia, los significados de la pedagogía e incluso las metodologías de trabajo en el proceso de enseñanza y aprendizaje fueron, y son aún, validadas y aplicadas bajo el amparo de los postulados científicos del pensamiento positivista, el cual continúa servil a los intereses del capitalismo dictaminando aquello que es civilizatorio o barbárico. El desafío para la creación de un nuevo sistema educacional consiste en adquirir un compromiso social, civil y profesional, pero, sobre todo, se requiere del deseo de crear nuevos saberes que sostengan alternativas que compitan con los diversos disfraces que la ideología neoliberal suele utilizar para influir en la normalización conveniente de la vida. Catherine Walsh (2009) en sus reflexiones sobre los conflictos que ha enfrentado para implementar el pensamiento 
intercultural, ejemplifica muy bien, como el capitalismo esconde sus intenciones a partir de la creación de nuevas lógicas que interpretan añoranzas de la comunidad. Por ejemplo, la idea de multiculturalidad, según Walsh (2009), fue impulsada como la nueva lógica de reconocimiento de los pueblos originarios en Latinoamérica y el Caribe, pero terminó siendo una nueva estrategia de dominación de los conflictos étnicos e incluso categorización étnica.

Los nuevos saberes en educación debieran surgir, entonces, de una investigación menos técnico administrativa, con investigadores e investigadoras que estén en y con los actores sociales del sistema escolar y no por sobre ellos. Lo que pasó y pasa con el sistema educativo chileno es la consecuencia de olvidar que el profesorado es un actor sociopolítico pensante que puede o no incidir, para bien o para mal, en lo que nos pase, o no, al interior de la sociedad. En estos nuevos caminos que emprende Chile, por ejemplo, acompañar a la nueva constitución, se hace urgente, desde la formación inicial y continua, volver a comprender que para colaborar en la construcción de la sociedad del mañana debemos, parafraseando a Paulo Freire (1978) no olvidar que la educación es siempre un quehacer político; desde esta consigna es posible repensar una educación más inmersa en los barrios, las calles, las comunidades. Michael Apple (2018), Falta referencia completa en la bibliografía contemporáneo de Freire, planteó que, un pedagogo crítico un profesor y una profesora reflexiva de su labor, debiera dejar el claustro de la sala de clases, la comodidad de la oficina y la sumisión a las normativas programáticas para interpretar, revivir y dar sentido, las veces que sean necesarias, a la labor que la escuela debe cumplir. La invitación, bajo las transformaciones sociales que están ocurriendo en Chile, es a pensar en lo posible en y desde la educación.

El sistema educativo, confiado en la ciencia positivista y sus directrices, articuló el ejercicio de la hegemonía. Gramsci (1981) definió la hegemonía como: "la capacidad de guiar, por lo tanto, implica dirección política, intelectual y moral" (p.25) de un hombre y una mujer que se constituyen en una comunidad sumisa, servil y creyente de toda aquella ilusión que el sistema entrega como opción de igualdad real. La escuela es un espacio de interacciones políticas, por ende, el profesorado es también un agente político que se constituye, en palabras de Gramsci (1990) como:

un creador, un suscitador, más no crea de la nada ni se mueve en el turbio vacío de sus deseos y sueños. El 'deber ser' es por consiguiente lo concreto o mejor, es la única interpretación realista e historicista de la realidad, la única historia y filosofía de acción, la única política (p. 38).

Bajo lo antes descrito es posible establecer que son los profesores y profesoras los y las que conocen de mejor forma esa realidad que se constituye entre las resistencias al poder de lo normativo al interior de las escuelas y las salas de clases. Es el profesorado el agente de cambio creador de nuevas posibilidades de futuro ya que, interpreta no desde la nada, sino desde la realidad. El profesorado posee lo que Hugo Zemelman (2012) y Estela Quintar (2008) Ilaman "conciencia histórica". Este conocimiento permite leer la realidad que nos rodea, cuestionar, pensar y proponer.

El hombre político y la mujer política, que antes fueron estudiantes, son la consecuencia de prácticas de enseñanza que surgieron de saberes pedagógicos o saberes de resistencia. Desde el 2021 los chilenos y chilenas aguardan con ilusión una nueva constitución, una 
renovada carta magna que se gesta en una profunda revisión de aquella cruel realidad impuesta desde la dictadura cívico - militar y experimentada durante los gobiernos del Chile democrático. Además, "la pandemia de coronavirus es una manifestación entre muchas del modelo de sociedad que comenzó a imponerse a nivel mundial a partir del siglo XVII y que ahora está llegando a su etapa final" (De Sousa Santos, 2020, p. 64). El fin del camino recorrido exige, llegado este momento, buscar nuevos rumbos.

\section{DIVERSIDAD, ESPACIO CONCEPTUAL QUE PROBLEMATIZA LA EDUCACIÓN CIUDADANA DEL CHILE QUE DESPERTÓ}

Las orientaciones ministeriales sobre la educación ciudadana establecen como uno de sus objetivos que "el proceso educativo tiene como finalidad formar personas ciudadanas y ciudadanos integrales que aporten al desarrollo de la sociedad" (MINEDUC, 2016, p. 14). En paralelo la Ley General de Educación (2009) propone que el proceso de enseñanza que cursan los y las estudiantes debiera apuntar a la formación en la convivencia, la participación de "forma responsable, tolerante, solidaria, democrática y activa en la comunidad (Ley 20.370, 2009)", por lo tanto, entre los objetivos de la enseñanza para la educación ciudadana está educar para la convivencia. Relacionarnos en una comunidad, que está en reconstrucción, como el caso de Chile, exige pensar en categorías conceptuales que permitan reflexionar en cómo, según Pilar Benejam (1999) “educamos a nuestros alumnos en la tolerancia, de manera que entiendan que la identidad está constituida por una suma de patrias, de lenguas, y de influencias" (p.67) es decir, vivir, convivir, hacer parte de la diversidad. Pero ¿Qué es posible relevar del concepto de diversidad que pueda constituir una nueva senda para la enseñanza de la ciudadanía? Comprender en profundidad lo que trasciende a la idea de diversidad es el primer intento para proyectar un nuevo espacio de pensamiento que permita crear conocimientos y propuestas que transformen la educación de ciudadanas y ciudadanos que no tan sólo comprendan las nuevas normas cívicas, sino que, además, hagan suyo los nuevos ideales de relaciones civiles que requiere el futuro en materia de entendimiento, convivencia y comprensión. En palabras de Humberto Maturana (2021): "Educar no es solo entregar conocimientos, es transformación en la convivencia" (p. 42).

Las autoridades político educativas en Chile, tienen un discurso que tiende a incluir la diversidad en el sistema educativo. Sin embargo, estos discursos no son más que palabras sin criterio de realidad que terminan por colisionar con un sistema educativo que, más aún bajo la actual coyuntura social, política y sanitaria, según Casasuss (2003) sigue siendo un reflejo de la desigualdad estructural del país. Por lo tanto, la idea de diversidad con la cual se convive en el sistema educativo puede ser explicado de la siguiente manera:

La concepción de diversidad que se operacionaliza en la política pública chilena responde, en general, a esta construcción normalidad- anormalidad/mismidadalteridad subalternizada, que resulta del posicionamiento epistemológico en el espacio de la objetividad. En consecuencia, los distintos gobiernos han buscado 
atender el problema de la diversidad, focalizándose en grupos que se perciben como diferentes de la norma, entendiendo su diferencia como déficit o como fuente de vulnerabilidad. (Druker, 2020, p. 203)

Bajo este escenario, una renovación de la educación para nuevos ciudadanos y ciudadanas, inicia por motivar el entendimiento de que "La diversidad podrá aparecer más o menos acentuada, pero es tan normal como la vida misma, y hay que acostumbrarse a vivir con ella y a trabajar a partir de ella" (Sacristán y Pérez, 1999, p. 2).

También Duschatzky y Skliar (2000) plantean que siempre será necesario cuestionar el lenguaje que rodea a los discursos sobre diversidad en especial cuando se trata de educar una nueva ciudadanía, ya que las palabras y sus acciones de enseñanza pueden constituirse en cimientos de "eufemismos que tranquilizan nuestras conciencias o levantan la ilusión de que asistimos a profundas transformaciones culturales simplemente porque nos arropamos con palabras de moda" (p.2).

Pensar en una nueva ciudadanía, a partir de la idea de diversidad, nos desafía a considerar que la comunidad política, en los ámbitos civil y cívico, debe considerarse como la consecuencia de un proceso de construcción al interior de todo lo que naturalmente es diverso. Nolfa Ibáñez (2006) plantea que la diversidad es "los modos distintos de construir significados que dan lugar a una visión de mundo diversa en algunos o en muchos sentidos, no mejor o peor sino solo diferente" (p. 70). La educación ciudadana debe promover la comprensión, a través de experiencias concretas, en el quehacer cotidiano de la escuela, fomentar un nuevo paradigma de comunidad que se constituye desde lo diverso. Es decir:

\begin{abstract}
Permitir al profesor o profesora recoger las experiencias y conocimientos previos de los estudiantes relativas al contenido que se tratará o a la actividad a realizar, e incorporarlos efectivamente a la clase, ya sea para ratificarlos, ampliarlos o modificarlos; cuestión que constituye un aspecto central en el trabajo pedagógico con la diversidad» (Ibáñez, 2010, p. 283).
\end{abstract}

Repensar los objetivos de la educación ciudadana escolar, en el marco de los cambios que vive Chile, no significa obviar todo lo ya propuesto en materia curricular y metodológica. La labor central es complementar y tensionar lo que existe con aquellas ideas que permitan una enseñanza de la ciudadanía que no renuncie a mirar su pasado didáctico y de fines de enseñanza, sin embargo, en el marco del pensar nuestra nueva comunidad social y política será requisito que todo lo que se enseñe, para ser aprendido, por los y las estudiantes, deberá tributar a los nuevos cimientos sociales de convivencia cívica y civil que, por ejemplo, la nueva constitución brindará. En este escenario la concepción de diversidad, que mejor ilumina esta idea de repensar la enseñanza ciudadana, es la propuesta por Nolfa Ibáñez (2010) entendida con una idea de diversidad como el lenguaje que emerge de la convivencia de los sujetos.

La idea de diversidad construida por Ibáñez cobra, para estas reflexiones, tremendo valor debido a que ella inicia su definición, de diversidad, inserto en un plano social lo que se construye en la relación en coexistencia. Además, si entendemos que la cultura es una creación humana, de la comunidad socio/política, entonces es posible creer en que es posible una nueva enseñanza y, por lo tanto, nuevos aprendizajes ciudadanos que se 
impulsen en una convivencia civil y cívica en el contexto de la natural diferencia biológica que nos constituye y nos pone en el mundo. Pensar desde la lógica propuesta por la doctora lbáñez, en los tiempos que corren, es sin duda un punto de partida para proponer nuevas perspectivas sobre lo que deseamos ser como país en un mundo que es para todas y todos los que deseen hacerse parte de la normal diversidad.

\title{
EDUCACIÓN INTERCULTURAL, IDEAS INICIALES PARA REFUNDAR LA EDUCACIÓN CIUDADANA
}

Existen diversos énfasis de educación ciudadana, algunos apuntan al desarrollo de conocimientos cívicos otros al desarrollo de habilidades civiles. Algunos enfoques potencian el valor de los derechos humanos y también la reflexión sobre la democracia. La literatura sobre formación ciudadana en definitiva es amplia. Existen trabajos relacionados con la revisión y profundización conceptual de ideas como: democracia, vida cívica y civil, política y participación (Cox, 2015); análisis e implicancias para el sistema escolar chileno de estudios internacionales de educación ciudadana (Agencia de la Calidad, 2016; Cox, 2010; Cox et. al., 2005); la formación ciudadana en el currículum escolar (Bascopé et. al., 2015); Cox y García, 2015; el desarrollo o profundización de las desigualdades sociales, políticas y económicas y su vinculación con la educación ciudadana (Cox et. al., 2015); Por otra parte, existen trabajos que han estudiado el pensamiento (concepciones y propósitos) del profesorado sobre la formación ciudadana (Altamirano y Pagés, 2018) y la relación de la enseñanza de la historia con el desarrollo ciudadano (Jara y Santisteban Pagès, 2016; Pagés, 2005; 2018; Pagés y Santisteban, 2009) El objetivo de este apartado aspira a repensar la educación ciudadana en las ideas de la interculturalidad debido a que el actual escenario socio político en Chile permite:

\begin{abstract}
Una oportunidad de replantearnos los modos institucionalizados de vivir juntos en sociedad y, consecuentemente, de problematizar el tipo de relaciones y las formas de conceptualizar lo propio (identidad) y lo ajeno (alteridad) promovidas en el principal espacio de formación de ciudadanos: la escuela (Ibáñez, et. al., 2012 p. 218).
\end{abstract}

La reconceptualización de la interculturalidad en Latinoamérica tiene un vasto recorrido intelectual (Mardones, 2017; Ibañez, 2010; Ibañez et. al. 2012; Rivera, 1999; Walsh 2009) La intención ha sido posicionar la interculturalidad tanto en comprensión conceptual y epistémica con el objetivo de convertir estas ideas en marcos referenciales con los cuales seguir un rumbo para, por ejemplo, una revisión de los fundamentos de la enseñanza ciudadana y pensar en un espacio de enseñanza que promueva "las relaciones positivas entre distintos grupos culturales, confrontar la discriminación, el racismo y la exclusión” (Walsh, 2009, p. 2) son desafíos que deben ser problematizados en el proceso de enseñanza y aprendizaje de la ciudadanía. Catherine Walsh (2009) plantea que considerando la interculturalidad es posible pensar en "formar ciudadanos conscientes de las diferencias y capaces de trabajar conjuntamente en el desarrollo del país y en la construcción de una sociedad justa, equitativa, 
igualitaria y plural" (p. 2) pero antes es necesario que la interculturalidad permee el proceso de enseñanza y aprendizaje de ciudadanos y ciudadanas en la escuela. Desde el Ministerio de Educación (MINEDUC) chileno existen normativas que reconocen la necesidad de considerar la implementación de la interculturalidad como una acción propia de la convivencia social. A propósito de lo antes señalado el MINEDUC plantea lo siguiente:

El desafío que la interculturalidad implica para las escuelas, radica en desarrollar competencias para la comprensión y valoración de la diferencia cultural como componente esencial de nuestras sociedades, donde se busca articular y validar el conocimiento indígena al mismo nivel que el conocimiento occidental, promoviendo el diálogo y el respeto por la diferencia. (2020, p.2)

A partir de lo antes descrito, es posible determinar que el MINEDUC reconoce la importancia de la interculturalidad como parte fundamental de la conformación de una nueva dinámica de relaciones políticas entre diversas culturas. También, es posible afirmar que el MINEDUC concibe una educación intercultural como parte fundamental de los sustentos para la adquisición de habilidades y valores adecuados para una nueva sociedad. En consecuencia, tensionar la idea de una nueva educación ciudadana, a la luz de las virtudes de la interculturalidad, es una acción justificada desde el rol que debe tener la educación como agente de cambio social. Adentrarse en estas reflexiones es pensar desde el ámbito educativo, pero sin perder el rol político que los educadores y las educadoras tienen. "La educación verdadera es praxis, reflexión y acción del hombre sobre el mundo para transformarlo" (Freire,1987, p.7).

Rivera (1999) concibe la interculturalidad como el proceso de integración, en todos los sectores de la sociedad. Integración que pone sus cimientos en el diálogo, la convivencia y toda aquella acción que considere una comunicación vinculante con toda cultura o cosmovisión. La base intransable de una nueva educación ciudadana debiera ser la que considera, en la formación de una nación, que somos un todo en comunicación vinculante, es decir, nos constituimos todos y todas en acciones consensuadas y no impuestas. En este sentido destacamos que las investigaciones con foco en interculturalidad han demostrado que:

En el último tiempo, investigadores y teóricos de la educación han desarrollado un concepto de interculturalidad diferente del que ha sido puesto en práctica en las reformas educativas latinoamericanas y que deriva de un marco epistemológico lejano del positivismo, el cual sitúa al sujeto como productor de realidades culturales diversas y a las culturas como procesos creativos, como movimientos permanentes de construcción, deconstrucción, definición y redefinición de identidad, conocimientos y ciudadanías. (Ibáñez et al., 2012, p. 218).

Las opciones que presentan los resultados de las investigaciones sobre interculturalidad permiten pensar en la ciudadanía que se desea. A la luz de los antecedentes descritos, teóricos y sociales, se hace necesario pensar en una ciudadanía intercultural. Considerar el sentido de las vidas significa atreverse a pensar en cómo logramos una nueva convivencia civil que potencie nuestra coexistencia cívica. Es decir, pensar en la normativa que mandate nuestras 
nuevas instituciones es un paso que debe ser acompañado de una ciudadanía intercultural la cual "Valora sobremanera la palabra puesta en diálogo [de las diversas culturas], a la búsqueda cooperativa de la verdad y la justicia". (Cortina, 2009, p.179).

\section{CONCLUSIONES QUE NO CONCLUYEN}

Integrar la profundidad y complejidad del concepto diversidad, en el marco de la formación para la ciudadanía, es la posibilidad de intencionar, desde una reflexión pedagógica el (re)encontrarnos y (re)construirnos como comunidad y nación. Transitar con el cambio epocal que experimenta Chile es necesario para pensar una educación y aprendizajes para la ciudadanía que se basen en lo heterogéneo, en los múltiples sentires sociales y en la natural diferencia que constituye una vida civil y cívica. Reencontrarnos, en este tiempo de necesarios cambios en Chile, implica mirarnos todas y todos para comprender que nuestros orígenes no necesariamente responden a la tradicional construcción de identidad nacional estandarizada. Un comienzo sería cuestionar la mirada homogenizadora impuesta por la estandarización de la ciencia positivista enquistada en las principales instituciones estatales y en especial en los centros educativos.

Incorporar la interculturalidad, al igual que la diversidad, en el marco de la enseñanza de la educación ciudadana, plantea la posibilidad de aprendizajes libres de estereotipos sobre una identidad nacional homogénea y excluyente. Permitiría la construcción de una nación inmersa en la riqueza de las múltiples maneras de concebir la vida social, es decir, el despliegue de todo lo que nos constituye o constituirá en una relación dinámica de respeto y consensuada como un nuevo pacto civil. El valor de lo antes mencionado está en la posibilidad de crear una alternativa que permita elegir algo más que solo los parámetros impuestos por el individualismo y el consumo.

Integrar a la interculturalidad en procesos de enseñanza y aprendizaje, pero como una cuestión fundante, permitiría pensar lo que este tiempo coyuntural exige pensar, ciudadanos y ciudadanas que articulan su existencia y convivencia en la multiplicidad de miradas - relacionales sobre quienes somos y de qué maneras podemos constituirnos a partir de los diversos legados culturales locales. Es decir, cómo evitamos el sometimiento cultural impuesto por un sistema neoliberal avalado por el racismo, la segregación y el control de toda expresión cultural local (Walsh, 2009) poner en evidencia el colonialismo que sufrimos en Chile, pero también confrontarlo pensando los ¿Qué enseñar? ¿Cómo enseñar? y con mayor énfasis el ¿Para qué enseñar?

A raíz de todo lo acontecido desde el estallido social, en octubre de 2019, millares de chilenos y chilenas instalaron, después de mucho tiempo, la real esperanza. La RAE define esperanza como "un estado de ánimo", "como un indicador probable de que algo pueda suceder" y también "esperar que aquello solicitado, anhelado pronto llegará". Es decir, la esperanza será más real y menos conceptual si desde la investigación educativa se levantan nuevas propuestas que apunten a la consolidación de aquello que comenzó a fraguarse en acción y dolor desde el 19 de octubre de 2019 en Chile, porque no bastará sólo con la nueva constitución. 


\section{REFERENCIAS}

Apple, Michael. (2018). ¿Puede la educación cambiar la sociedad?. Santiago de Chile: LOM. Altamirano, M. y Pagés, J. (2018). Pensamiento del profesorado de historia geografía y ciencias sociales sobre la formación ciudadana en Chile. Clío y Asociados. La historia enseñada. Enero-junio. (pp. 24 - 37).

Bauman, Z. (1999). En búsqueda de la política. Buenos Aires: FCE.

Benejan, P. (1999). El conocimiento Científico y Didáctico de las Ciencias sociales para el siglo XXI. En Teresa García Santa María (coord.) Un currículum de Ciencias Sociales para el siglo XXI.¿Qué contenidos y Para qué? España: Universidad de la Rioja/ Diada Editores (pp. 15 - 25).

Bourdieu, P. (2012). Sobre el Estado. Cursos en el Collège de Francia. Barcelona: Anagrama. Bourdieu, P. (2012). Bosquejo de una teoría de la práctica. Buenos Aires: Prometeo Libros.

Calvo, C. (2012). Del mapa escolar al territorio Educativo. Disoñando la Escuela desde la Educación. La Serena, Chile: Editorial Universidad de la Serena.

Casasuss, J. (2003). La escuela y la (des)igualdad. Santiago: LOM ediciones.

Cox, C. Castillo, J. (2015). Aprendizaje de la ciudadanía. Contextos, experiencias y resultados. Santiago: Ediciones UC.

Cortina, A (2009). Ciudadanos del Mundo, Hacia una teoría de la Ciudadanía. Madrid: Alianza editorial.

Dávila, X. Maturana, H. (2015). Reflexiones biológico - filosóficas, los mundos de nuestro vivir biológico - cultural. Boletín del Museo Nacional de Historia Natural, Chile, 64. (pp. 81-99).

Duschatzky, S. Skliar, C (2000). La diversidad bajo sospechas Reflexiones sobre los discursos de la diversidad y sus implicancias educativas. https://aulavirtual.agro.unlp.edu.ar/pluginfile. php/16763/mod_resource/content/1/LA\%20DIVERSIDAD\%20BAJO\%20SOSPECHA.pdf

De Sousa Santos, B. (2020). La cruel Pedagogía del Virus. Buenos Aires: CLACSO.

De Sousa Santos, B., Grijalva, A. (2012). Justicia indígena, plurinacionalidad e interculturalidad en Ecuador. Quito: Ediciones Abya Yala.

Druker, S. (2020). El giro epistemológico: De la diversidad de los otros a la diversidad como condición del encuentro. Revista de Estudios y Experiencias en Educación. 19 (39) abril. (pp. 227 - 239).

Foucault, M. (1984). Vigilar y castigar. El nacimiento de la prisión. Bogotá: Siglo XXI.

Foucault, M. (1997). Política y Educación. Buenos Aires: Siglo XXI Editores.

Foucault, M. (1981). Cuadernos desde la cárcel. Puebla: Universidad Autónoma de Puebla.

Foucault, M. (1990). La política y el estado moderno. Puebla: Premia.

Grundy, S. (1998). Producto o praxis del currículum. Madrid: Morata.

Habermas, J. (1972) Knowledge and Human Interests. United Kingdom.

Ibáñez, N. Diaz, T. Druker, S. Rodríguez, M. (2012). La comprensión de la Diversidad en interculturalidad y Educación. Convergencia, Revista de Ciencias Sociales. 59 (pp. 215 244).

Ibáñez, N. (2010). El contexto interaccional y la diversidad en la escuela. Estudios Pedagógicos. XXXVI, (1) (pp. 275-286).

Ibáñez, N., Díaz, S. Druker, S. Rodríguez, M. Smith, C. (2008). Saber pedagógico y práctica docente: Estudio en aulas de educación parvularia y básica. Colección I + I. Santiago: DIUMCE. 
Ibáñez, N. (2006). La comprensión de lo diverso como condición de la calidad educativa. Investigaciones en Educación. VI (2).

Lander, E. (2000). La colonialidad del saber: eurocentrismo y ciencias sociales. Perspectivas latinoamericanas. Caracas: FACES-UCV/IESALC.

Ley 20.370 (2009). Establece la Ley General de Educación.

Ley 20.911 (2016). Establece el Plan de Formación Ciudadana.

Mardones, T. (2017). Educación Intercultural en el Currículum Nacional Chileno. Revista Intersecciones Educativas. 7 (1) (pp. 69-84).

Maturana, H. Dávila, X. (2021). La revolución Reflexiva. Santiago: Editorial PAIDÓS.

Maturana, H. Dávila, X. (2019). Historia de nuestro vivir cotidiano. Santiago: Editorial PAIDÓS. Matamala, D. (2019). La ciudad de la Furia. Santiago: Editorial Catalonia.

Ministerio de Educación de Chile. (2016a). Orientaciones para la elaboración del Plan de Formación Ciudadana. Santiago de Chile: Ministerio de Educación, División de Educación General.

Ministerio de Educación de Chile (2020). Educación Intercultural. Programa de Educación Intercultural Bilingüe. Santiago: Ministerio de Educación.

Morin, E. (1990). Introducción al Pensamiento complejo. Barcelona: GEDISA.

Morin, E. (1999). Los siete Saberes Necesarios para la Educación del Futuro. UNESCO.

Ordoñez, P. (2014). Cauce y Río: una Poética Pedagógica del Presente. Revista educación y Ciudad. (26) (pp. 131 - 136).

Pagés, J. (2015). Ciudadanía y enseñanza de la historia. Revista de la Asociación de profesores de enseñanza de la historia de universidades nacionales Argentina. (1) (pp. 11- 42).

Paredes, J.P. (2013). El presente potencial y la conciencia histórica: realidad social, sujeto y proyecto. A la memoria de Hugo Zemelman Merino. Polis, Revista Latinoamericana. 12 (36) (pp. 243-261).

Quintar, E. (2008). Didáctica no parametral: senderos hacia la descolonización. Manizales: IPECAL/ Universidad de Manizales.

Rivera C. (1999). Anotaciones fragmentarias en torno a la interculturalidad. En: García Blanco, M. A. (comp.). Encuentro México-Bolivia sobre cultura, identidad y globalización. La Paz: Uma Phajsi Ediciones.

Sacristán, J. G., Ángel I. Pérez G. (1999). Comprender y transformar la enseñanza. España: Morata.

Salazar, G. (2020). Acción Constituyente. Un texto ciudadano y dos ensayos históricos. Santiago: Tajamar Editores.

Walsh, C. (2009). Interculturalidad Crítica y Educación Intercultural. Seminario "Interculturalidad y Educación Intercultural", organizado por el Instituto Internacional de Integración del Convenio Andrés Bello, La Paz, 9-11 de marzo.

Zemelman, H. (2012). Los horizontes de la razón. Uso crítico de la teoría. I. Dialéctica y apropiación del presente. Barcelona: Ed. Anthropos.

Zemelman, H. (2007). Conversaciones acerca de interculturalidad y conocimiento. México: Ipecal/Instituto Politécnico Nacional. 